\title{
Effect of Time and Amount of Colostrum Feeding on Physiological Parameters and Health Scores in Surti Buffalo Calves
}

\begin{abstract}
Background: Timely feeding of adequate colostrum to new born calf is important to ensure transfer of passive immunity to prevent several infections. Present study has evaluated effect of time and amount of colostrum feeding on physiological parameters and health scores in Surti buffalo calves.

Methods: Based on amount and time of feeding colostrum after birth, 24 Surti buffalo calves were divided into four groups as $T_{1}(7 \%$; $0-4), T_{2}(7 \% ; 4-8), T_{3}(10 \% ; 0-4)$ and $T_{4}(10 \% ; 4-8)$. Physiological parameters (twice daily upto day 5$)$ and naval, nasal, eye and faecal scores on day $1,7,14,21,28,35$ and 42 were recorded. Lying behavior was recorded on day 2.

Result: Significant $(p<0.05)$ interaction between treatment and weeks and nonsignificant effect of treatment was observed. Calves that received colostrum late had significantly $(p<0.05)$ higher faecal score as well as evening heart and respiration rate. Calves that received colostrum early had significant $(p<0.05)$ higher lying time. Normal scores of naval, nasal, eye and faecal indicated good health of calves. It was concluded that early feeding of colostrum @ 7 or $10 \%$ body weight within 4 hours after birth is beneficial for optimum health in buffalo calves.
\end{abstract}

Key words: Health score, Lying behavior, Passive immunity, Physiological parameters, Surti buffalo calves.

\section{INTRODUCTION}

Feeding of adequate colostrum within 2-4 hours after birth to newborn calves is critical for their survivability and subsequent health at least during initial 45 days of life. Timely and adequate colostrums intake most critical management aspect affecting morbidity and mortality in preweaned calves (Singh et al., 2011). Good colostrum management also depends on quality and quantity of colostrum feeding. Any impairment in it leads to failure in transfer of passive immunity (FTP). FTP is associated with higher occurrence of diarrhoea, pneumonia, naval ill, high morbidity and mortality (Dunn et al., 2017 and Weiller et al., 2020). Health status and chances of survival of neonatal calves is affected by one of the most important management aspect of early and sufficient intake of high quality colostrum (Godden et al., 2019). Most of progressive livestock keepers and farm managers are aware but have a tendency to ignore its importance. Therefore sporadic cases of FTP in calves are common in India. Not only there is a general delay of colostrum feeding by 12 or more hours in rural areas but also its quantity sucked by calf might be below the required amount. However colostrum intake by suckled calves is more than that by weaned calves (Singh et al., 2019) that necessitates manual feeding after suckling. Calves may bear the brunt of FTP but many a time they are able to survive. However they may suffer from disease conditions like naval ill, respiratory diseases, conjunctivitis and calf scours. Occurrence of these conditions can be evaluated without clinical signs by health scoring system in Surti buffalo calves (Sorathiya et al., 2019). Calves were diagnosed with either
${ }^{1}$ College of Veterinary Science and Animal Husbandry, Navsari396 450, Gujarat, India.

${ }^{2}$ Livestock Research Station, Navsari Agricultural University, Navsari-396 450, Gujarat, India.

${ }^{3}$ Post-Graduate Institute of Veterinary Education and Research, Kamdhenu University, Rajpur (Nava)-383 001, Himatnagar, Gujarat, India.

Corresponding Author: V.K. Singh, College of Veterinary Science and Animal Husbandry, Kamdhenu University, Navsari-396 450, Gujarat, India. Email: drvksingh1981@gmail.com

How to cite this article: Patel, P.B., Patel, N.B., Sorathiya, L.M., Singh, V.K. and Rao T.K.S. (2022). Effect of Time and Amount of Colostrum Feeding on Physiological Parameters and Health Scores in Surti Buffalo Calves. Indian Journal of Animal Research. DOI: $10.18805 / I J A R . B-4720$.

Submitted: 13-07-2021 Accepted: 27-11-2021 Online: 11-01-2022

pneumonia or diarrhoea when they had a total respiratory score (combined cough, highest ear or eye score and nasal discharge score) of at least 4 or a fecal score of at least 2 respectively (Priestley et al., 2013). Studies for effect of full or partial FTP on calf health in first month specific to Indian scenario are scarce. Hence this study was planned to evaluate effect of colostrum feeding time and amount on physiological parameters and health scores in Surti buffalo calves.

\section{MATERIALS AND METHODS}

Present study was conducted from January to March, 2020 on 24 Surti buffalo calves of either sex maintained at 
Livestock Research Station, Navsari Agricultural University, Navsari, Gujarat. All pregnant buffaloes were kept in calving pen and monitored continuously round the clock with the help of attendants and CCTV cameras. Soon after calving identification numbers were given to all calves. Surti buffalo is well known buffalo breed of India characterized by gray color, sickle shape horn and two collar belts at neck region. It is small sized buffalo breed, average weight of adult female is around $400 \mathrm{~kg}$. It is regular calver and average lactation yield is about 1500 liter. Average birth weight of selected calves was $24.25 \mathrm{~kg}$. Four treatment groups on the basis of colostrum fed were: $\mathrm{T}_{1}\left(7 \%\right.$ of calf BW at $0-4 \mathrm{~h}$ of birth, $\mathrm{V}_{7}$, $\left.T_{0-4}\right), T_{2}\left(7 \%\right.$ of calf BW at $4-8 \mathrm{~h}$ of birth, $\left.V_{7}, T_{4-8}\right), T_{3}(10 \%$ of calf $B W$ at $\left.0-4 h, V_{10}, T_{0-4}\right)$ and $T_{4}(10 \%$ of calf $B W$ at $4-8 \mathrm{~h}$, $\mathrm{V}_{10}, \mathrm{~T}_{4-8}$ ) of birth.

Calves belonging to 0-4-hour groups $\left(T_{1}\right.$ and $\left.T_{3}\right)$ were kept with dam and allowed to suck during letdown. Calves of 4-8 hour groups $\left(T_{3}\right.$ and $\left.T_{4}\right)$ were allowed to suck after 4 hours of birth. After letdown, about 1.5 -liter colostrum was milked for subsequent usage in the same calf. All calves were weighed before and after sucking to determine the quantity of colostrum sucked. Colostrum sucked by all calves was less than $50 \%$ of their requirement hence they were fed colostrum by bottle as first dose. Remaining half of the amount of colostrum was fed to all calves within 24 hours in two doses with the help of bottles. To evaluate general health in calves physiological parameters like rectal temperature, respiration rate and heart rate were recorded twice daily in morning (9-10 am) and evening (4-5 pm) for 5 days after birth. To assess subsequent health of calves following scores were recorded by expert after 24 hours from feeding of first dose (day 1) and on day 7, 14, 21, 28, 35 and 42 as per standard method with slight modification (Table 1). On the second day sitting behavior of all calves were recorded with the help of IP based CCTV cameras.

Table 1: The scoring chart based on clinical observation.

\begin{tabular}{lcl}
\hline Criteria & Score & Clinical observation for scoring \\
\hline Navel inspection & 1 & Normal \\
& 2 & Slightly inflamed \\
& 3 & Heavily inflamed with abscess \\
Nasal discharge & 4 & Ripen abscess with pus \\
& 1 & Normal \\
& 2 & Small Amount of cloudy discharge \\
& 3 & Bilateral, cloudy, or excessive mucus \\
& & discharge \\
& 4 & Copious bilateral mucopurulent discharge \\
& 1 & No discharge \\
& 2 & Small amount of ocular discharge \\
& 3 & Moderate amount of bilateral discharge \\
& 4 & Heavy ocular discharge respectively \\
Fecal discharge & 1 & Normal (dry and hard) \\
& 2 & Soft (soft and formed to pasty) \\
& 3 & Loose (mix with liquid and solid) \\
& 4 & Watery (liquid and watery) \\
\hline
\end{tabular}

Statistical analysis of obtained periodic repeated data of physiological and health observations was carried out by using repeated means ANOVA under GLM using IBM SPSS version 26 software. Estimated Marginal Means were used to compare treatment means. Tukey's-test was used for comparing means. Multivariate test in general linear model was conducted to know the interaction of treatment means with periods.

\section{RESULTS AND DISCUSSION}

\section{Health scores}

Results for frequency of health score with respect to various treatments are presented in Table 2 and mean health scores affected by treatments are presented in Table 3 . Table 2 reveals that naval, nasal, eye and fecal scores of 1 found in $83,74,74$ and $74 \%$ calves, respectively, indicated overall good health status in all the calves. Further, score 4 was not observed in any irrespective of health score. Naval health is very important for survival of calves. High frequency of naval score 1 was observed in calves of $\mathrm{T}_{3}(95 \%)$ followed by $\mathrm{T}_{1}(86 \%)$. Score of 2 and 3 were more in group $\mathrm{T}_{2}$ and $\mathrm{T}_{4}$ indicating that calves receiving colostrum late had higher naval score.

Nasal score is an indicator for respiratory health as pneumonia is a major cause of calf mortality (Patel et al., 2017). High frequency of nasal score 1 was found in calves of $\mathrm{T}_{3}(86 \%)$ followed by $\mathrm{T}_{1}(83 \%)$ whereas, score 2 and 3 were found to be higher in $\mathrm{T}_{2}$ and $\mathrm{T}_{4}$ demonstrating that calves receiving colostrum late had higher nasal discharge and thus they are more likely to suffer from respiratory infections. Likewise eye and faecal scores also showed similar trend of lower frequency for score 2 and 3 in group $T_{1}$ and $T_{3}$. Perusal of frequency of various health score studied showed that time of colostrum feeding is more important for good health of calf for first 45 days. Bahri et al, (2016) reported positive and significant correlation between serum IgG levels of calf and dam after colostrum was fed to calves adequately and timely. Similarly Furman-fratczak et al. (2011) found more clinical cases of diarrhoea and respiratory infections in calves with less $\lg \mathrm{G}$ at birth $(<5 \mathrm{~g} / \mathrm{L})$. They also observed that the ability of calves to ingest colostrum early was associated with desired health score in more calves.

Means of health scores affected by colostrum feeding treatments is shown in Table 3. Grand means of naval score, nasal score, eye score and faecal score ranged from 1.201.39. Amongst scores faecal score was highest whereas naval score was lowest. Higher naval score was observed in $T_{4}$ but it was nonsignificant. Naval score within treatment between all 7 observations and their interaction was nonsignificant. The reason for this could be that naval health protocol in all calves at studied farm is being followed. Nasal score was highest in $\mathrm{T}_{4}$. Treatment and week effect on nasal score was nonsignificant. However interaction between treatment and week was significant showing that treatment means were significant for some seven weekly observations. 
Effect of Time and Amount of Colostrum Feeding on Physiological Parameters and Health Scores in Surti Buffalo Calves

Results reveal higher means between third and fourth weeks. Eye score was also nonsignificant between treatments and weeks. Interaction between treatment and week was significant. Eye secretion and nasal discharge are indicative of respiratory diseases. However results showed that respiratory health score was almost normal across all treatments without any effect of treatment. Dunn et al. (2017) also found similar respiratory health in calves either fed with 5 or $10 \%$ colostrum. In agreement to present findings Conneely et al. (2014) didn't found any difference in health scores in calves fed with either $7 \%$ or $10 \%$ colostrum that might be associated with enough IgG concentration in calves that received $7 \%$ colostrum. Hence due to good PIT the health of calves remained good and there was nonsignificant difference between treatments.

Faecal score was significantly higher in calves of groups $\mathrm{T}_{2}$ and $\mathrm{T}_{4}$ in which colostrum was fed late. Means between studied weeks along with interaction with treatment were significant. It shows that calves having FTP have more prone to suffer from diarrhoea. Data revealed more faecal score for 3-4 weeks after birth. Observed pooled faecal score and nasal score irrespective of treatment is in accordance with Scoley et al. (2019). Similar to present findings Priestley et al. (2013) also used health scoring system for studying failure of passive transfer in calves and they reported increased $(\mathrm{P}<0.03)$ morbidity and mortality in groups of

Table 2: Frequency of health score affected by time and amount of colostrum feeding in buffalo calves.

\begin{tabular}{|c|c|c|c|c|c|c|c|c|c|c|c|}
\hline \multirow{3}{*}{$\begin{array}{l}\text { Name of } \\
\text { health score }\end{array}$} & \multirow{3}{*}{ Score } & \multicolumn{8}{|c|}{ Treatment } & \multirow[b]{3}{*}{$\mathrm{n}$} & \multirow{3}{*}{$\begin{array}{l}\text { Poolec } \\
\% \\
\end{array}$} \\
\hline & & \multicolumn{2}{|c|}{$\begin{array}{c}\mathrm{T}_{1} \\
(7 \% ; 0-4)\end{array}$} & \multicolumn{2}{|c|}{$\begin{array}{c}\mathrm{T}_{2} \\
(7 \% ; 4-8)\end{array}$} & \multicolumn{2}{|c|}{$\begin{array}{c}\mathrm{T}_{3} \\
(10 \% ; 0-4)\end{array}$} & \multicolumn{2}{|c|}{$\begin{array}{c}\mathrm{T}_{4} \\
(10 \% ; 4-8)\end{array}$} & & \\
\hline & & $\mathrm{n}$ & $\%$ & $\mathrm{~N}$ & $\%$ & $\mathrm{n}$ & $\%$ & $\mathrm{n}$ & $\%$ & & \\
\hline \multirow[t]{3}{*}{ Naval score } & 1 & 36 & 86 & 33 & 79 & 40 & 95 & 30 & 71 & 139 & 83 \\
\hline & 2 & 6 & 14 & 8 & 19 & 2 & 5 & 9 & 21 & 25 & 15 \\
\hline & 3 & 0 & 0 & 1 & 2 & 0 & 0 & 3 & 7 & 4 & 2 \\
\hline \multirow[t]{3}{*}{ Nasal score } & 1 & 35 & 83 & 24 & 57 & 36 & 86 & 29 & 69 & 124 & 74 \\
\hline & 2 & 4 & 10 & 14 & 33 & 5 & 12 & 10 & 24 & 33 & 20 \\
\hline & 3 & 3 & 7 & 4 & 10 & 1 & 2 & 3 & 7 & 11 & 7 \\
\hline \multirow[t]{3}{*}{ Eye score } & 1 & 33 & 79 & 26 & 62 & 36 & 86 & 30 & 71 & 125 & 74 \\
\hline & 2 & 8 & 19 & 12 & 29 & 5 & 12 & 10 & 24 & 35 & 21 \\
\hline & 3 & 1 & 2 & 4 & 10 & 1 & 2 & 2 & 5 & 8 & 5 \\
\hline \multirow[t]{3}{*}{ Fecal score } & 1 & 33 & 79 & 26 & 62 & 36 & 86 & 30 & 71 & 125 & 74 \\
\hline & 2 & 8 & 19 & 12 & 29 & 5 & 12 & 10 & 24 & 35 & 21 \\
\hline & 3 & 1 & 2 & 4 & 10 & 1 & 2 & 2 & 5 & 8 & 5 \\
\hline
\end{tabular}

Table 3: Effect of time and amount of colostrum feeding on health scores in buffalo calves.

\begin{tabular}{|c|c|c|c|c|c|c|}
\hline \multirow{2}{*}{$\begin{array}{l}\text { Health } \\
\text { parameter }\end{array}$} & \multicolumn{6}{|c|}{ Treatment means and standard error of means } \\
\hline & $\begin{array}{c}\mathrm{T}_{1} \\
(7 \% ; 0-4)\end{array}$ & $\begin{array}{c}\mathrm{T}_{2} \\
(7 \% ; 4-8)\end{array}$ & $\begin{array}{c}T_{3} \\
(10 \% ; 0-4)\end{array}$ & $\begin{array}{c}T_{4} \\
(10 \% ; 4-8)\end{array}$ & SEM & $T^{*} \mathrm{~W}$ \\
\hline Naval score & 1.14 & 1.24 & 1.05 & 1.36 & 0.12 & NS \\
\hline Nasal Score & 1.24 & 1.52 & 1.17 & 1.38 & 0.16 & * \\
\hline Eye score & 1.24 & 1.48 & 1.17 & 1.33 & 0.15 & * \\
\hline Faecal Score & $1.33^{\mathrm{ab}}$ & $1.55^{\mathrm{b}}$ & $1.21^{\mathrm{a}}$ & $1.48^{\mathrm{b}}$ & 0.07 & ** \\
\hline
\end{tabular}

Mean bearing different superscript across the rows differ significantly at $(p<0.05)$

Table 4: Effect of time and amount of colostrum feeding on physiological parameters in buffalo calves.

\begin{tabular}{lccccc}
\hline Physiological & \multicolumn{4}{c}{ Treatment means and standard error of means } \\
\cline { 2 - 6 } parameter & $\mathrm{T} 1$ & $\mathrm{~T} 2$ & $\mathrm{~T} 3$ & $\mathrm{~T} 4$ \\
& $(7 \% ; 0-4)$ & 100.8 & 100.4 & 100.6 & SEM \\
\hline Morning body temp $\left({ }^{\circ} \mathrm{F}\right)$ & 100.9 & 101.1 & 100.6 & 100.9 & 0.17 \\
Evening body temp $\left({ }^{\circ} \mathrm{F}\right)$ & 101.0 & 58.5 & 55.9 & 57.5 & 0.16 \\
Morning Res Rate & 55.7 & $61.9^{\mathrm{b}}$ & $58.1^{\mathrm{a}}$ & $61.2^{\mathrm{b}}$ & 0.84 \\
Evening Res Rate & $57^{\mathrm{a}}$ & 120.5 & 117.2 & 118.3 & 1.27 \\
Morning Heart Rate & 116.7 & $126.0^{\mathrm{b}}$ & $120.7^{\mathrm{a}}$ & $124.8^{\mathrm{b}}$ & 1.00 \\
Evening Heart Rate & $118.4^{\mathrm{a}}$ & & & \\
\hline
\end{tabular}

Mean bearing different superscript across the rows differ significantly at $(p<0.05)$. 
Table 5: Effect of time and amount of colostrum feeding on lying in buffalo calves.

\begin{tabular}{ll}
\hline Treatments & Lying time (minutes/24 hours) \\
\hline$T_{1}\left(V_{7} T_{0-4}\right)(n=6)$ & $1088.33^{\mathrm{a}} \pm 17.59$ \\
$T_{2}\left(V_{7} T_{4-8}\right)(n=6)$ & $1235.00^{\mathrm{b}} \pm 12.85$ \\
$T_{3}\left(V_{10} T_{0-4}\right)(n=6)$ & $1083.33^{\mathrm{a}} \pm 15.85$ \\
$T_{4}\left(V_{10} T_{4-8}\right)(n=6)$ & $1213.33^{\mathrm{b}} \pm 20.60$ \\
Overall $(n=24)$ & $1155.00 \pm 16.53$ \\
\hline
\end{tabular}

Mean bearing different superscript across the column differ significantly at $(p<0.05)$.

calves with FTP as compared to calves without failure of passive transfer. Weiller et al. (2020) showed that diarrhoea and respiratory diseases were $77.9 \%$ and $49.6 \%$, respectively in calves with FTP. Dunn et al. (2017) revealed higher incidences of enteritis in calves fed less colostrum i.e. @ $5 \%$ of BW compared to $10 \%$ BW. Their reports of respiratory and diarrhoea scores as well as clinical cases being higher than present finding might be due to species difference as the present study was hardy indigenous buffalo species. Significant higher faecal score in calves fed with $7 \%$ colostrum after 4 hours of birth might be associated with enteric $E$. coli infection that is most commonly prevalent. To combat enterotoxigenic E.coli infection in neonatal calves, they need anti-K99 antibodies which are available when calves receive sufficient lgG level (Alo et al., 2018).

\section{Physiological parameters}

Results for rectal temperature, respiratory rate and heart rates of calves are presented in Table 4. The perusal of the data showed that rectal temperature of calves in morning and evening was nonsignificant across all groups. Grand means of morning and evening temperature $\left({ }^{\circ} \mathrm{F}\right)$ were $100.7 \pm 0.09$ and $100.9 \pm 0.08$, respectively showing higher but nonsignificant evening temperature. Observed temperatures were in normal range. Neither there was effect of days or nor interaction was observed. Effect of amount and timing of feeding colostrum was nonsignificant on morning respiratory rates. However morning respiratory rates between days were significant. Evening respiratory rate was significantly lower in calves fed with colostrum within 4 hours after birth which is indicative of lower stress in calves of those groups. Overall morning and evening respiratory rates were $56.9 \pm 0.42$ and $59.5 \pm 0.34$ respectively. Heart rates in morning were observed in range of 116.7-120.5, that were statistically nonsignificant between treatment, day and interaction. Evening heart rate was significantly higher in calves with FTP groups $\left(T_{2}\right.$ and $\left.T_{4}\right)$ that received colostrum late thus hinting stress in calves of FTP group. Hadorn et al. (1997) reported that the calves receiving good PIT had significantly higher rectal temperature, heart rate and respiration rate as compared to calves of FTP group. Grand means of heart rate in morning and evening were 118.2 \pm 0.60 and $122.5 \pm 0.50$ respectively. Scoley et al. (2019) revealed similar physiological results in calves.

\section{Lying behavior}

Lying behaviour judged by observing lying time affected by colostrum feeding treatments during 24 hours period is presented in table 5 . It shows that lying time was significantly $(p<0.05)$ higher in calves of $T_{2}$ and $T_{4}$ as compared to calves of $T_{1}$ and $T_{3}$. More activity implies lesser sitting time and thus is indicative of good vigour and better activity which was seen in calves fed early with colostrum. Calves in which colostrum was fed after 4 hours of birth remain active for only around 3 hours as compared to 6 hour activity in groups fed early with colostrum. Observed activity of lying in calves in the present study was similar to the findings of Sorathiya et al. (2019). Lying behavior affected by feeding regime reported in present study is in accordance with Scoley et al. (2019).

\section{CONCLUSION}

It was concluded that early feeding of colostrum @ 7 or $10 \%$ body weight within 4 hours after birth is beneficial for optimum health of buffalo calves as indicated by physiological parameters, attaining better health scores and optimal lying behavior up to 45 days of age.

\section{ACKNOWLEDGEMENT}

Authors thank the Dean, College of Veterinary Science and Animal husbandry, Navsari and Navsari Agricultural University for the facilities provided for this research work.

\section{REFERENCES}

Alo, K., Nikbakhat, G., Lotfollahzadeh, S., Moosakhani, F. and Gharabaghi, A. (2018). Passive protective effect of antiK99 antibodies against enterotoxigenic $E$. coli infection in neonatal calves. Iranian Journal of Veterinary Medicine. 12(2): 97-107.

Bahri, B., Vecihl, A., Ibrahim, T., Sellm, D., Halit, M. and Ikram, C. (2016). Comparison of immunoglobulin ( $\operatorname{lgG}, \operatorname{lgM})$ concentrations in calves raised under organic and conventional conditions. Indian Journal of Animal Research. 50(6): 995-999.

Conneely, M., Berry, D.P., Murphy, J.P., Lorenz, I., Doherty, M.L. and Kennedy, E. (2014). Effect of feeding colostrum at different volumes and subsequent number of transition milk feeds on the serum immunoglobulin $\mathrm{G}$ concentration and health status of dairy calves. Journal of Dairy Science. 97(11): 6991-7000.

Dunn, A., Ashfield, A., Earley, B., Welsh, M., Gordon, A., McGee, M. and Morrison, S.J. (2017). Effect of concentrate supplementation during the dry period on colostrum quality and effect of colostrum feeding regimen on passive transfer of immunity, calf health and performance. Journal of Dairy Science. 100(1): 357-370.

Furman-Fratczak, K., Rzasa, A. and Stefaniak, T. (2011). The influence of colostral immunoglobulin concentration in heifer calves' serum on their health and growth. Journal of Dairy Science. 94(11): 5536-5543.

Godden, S.M., Lombard, J.E. and Woolums, A.R. (2019). Colostrum Management for Dairy Calves. Veterinary clinics of North America: Food Animal Practice. 35(3): 535-556. 
Effect of Time and Amount of Colostrum Feeding on Physiological Parameters and Health Scores in Surti Buffalo Calves

Hadorn, U., Hammon, H., Bruckmaier, R.M. and Blum, J.W. (1997). Delaying colostrum intake by one day has important effects on metabolic traits and on gastrointestinal and metabolic hormones in neonatal calves. The Journal of Nutrition. 127(10): 2011-2023.

Patel, M.D., Tyagi, K. and Sorathiya, L.M. (2017). Mortality pattern in an organized herd of Surti buffaloes of south Gujarat. Indian Journal of Animal Production and Management. 33(3-4): 40-47.

Priestley, D., Bittar, J.H., Ibarbia, L., Risco, C.A. and Galvao, K.N. (2013). Effect of feeding maternal colostrum or plasmaderived or colostrum-derived colostrum replacer on passive transfer of immunity, health and performance of preweaning heifer calves. Journal of Dairy Science. 96(5): 3247-3256.

Scoley, G., Gordon, A. and Morrison, S. (2019). Using Non-Invasive Monitoring Technologies to Capture Behavioural, Physiological and Health Responses of Dairy Calves to Different Nutritional Regimes during the First Ten Weeks of Life. Animals. 9(10): 760 .
Singh, A.K., Pandita, S., Vaidya, M.M., Singh, S.V., Chandra, G., Pampoori, Z.A., Huozha, R., Pathan, M.M., Kushwaha, R. and Sharma, V.K. (2011). Bovine colostrum and neonate immunity- A review. Agricultural Reviews. 32(2): 79-90.

Singh, P.K., Kamboj, M.L., Chandra, S., Kumar, A. and Kumar, N. (2019). Influence of weaning on growth, health and behaviour of buffalo (Bubalus bubalis) calves. Indian Journal of Animal Research. 53(5): 680-684.

Sorathiya, L.M., Raval. A.P., Kharadi, V.B., Tyagi, K.K. and Patel, M.D. (2019). Effect of flooring on growth performance, behaviour, health and economics in Surti buffalo calves during winter. Indian Journal of Animal Sciences. 89(11): 1246-1250.

Weiller, M.A.A., Moreira, D.A., Bragança, L.F., Farias, L.B., Lopes, M.G., Bruhn, F.R.P., Brauner, C.C., Schmitt, E., Corrêa, M.N., Rabassa,V.R. and Del Pino, F.A.B. (2020). The occurrence of diseases and their relationship with passive immune transfer in Holstein dairy calves submitted to individual management in southern Brazil. Arquivo Brasileiro de Medicina Veterinária e Zootecnia. 72(4): 1075-1084. 